\title{
David Jorge, Inseguridad colectiva. La Sociedad de Naciones, la guerra de España y el fin de la paz mundial, Valencia, Tirant Humanidades, 2016, 783 pp., ISBN: 978-841-655-647-2
}

Fabián Herrera León*

La editorial valenciana Tirant Humanidades publicó a finales de 2016 una extensa y atractiva obra sobre la guerra de España (1936-1939) y su desarrollo diplomático en el marco de la Sociedad de Naciones. Este libro lleva el título Inseguridad colectiva. La Sociedad de Naciones, la guerra de España y el fin de la paz mundial y está firmado por David Jorge, un historiador con no pocos méritos académicos (miembro de la World Association for International Studies, director de H-Spain, impulsor en México del Seminario de Historia Internacional) y firme desenvolvimiento profesional (en universidades y centros de investigación en Madrid, Connecticut y México), a quien tuve el gusto de conocer precisamente cuando concluía en la Ciudad de México su tesis doctoral bajo la dirección del reconocido historiador español Ángel Viñas. Este libro es una versión posterior, ampliada, mejorada y finalmente avalada por el comité científico de Tirant Humanidades. Lo considero, en general, un acierto editorial, pues cubre un enorme vacío historiográfico en la línea de conocimiento sobre la dimensión exterior del conflicto español, lo suficiente para cubrir el plano ginebrino de discusión. La omisión en casi toda la historiografía de esta naturaleza equivale a un error grave finalmente enmendado por este dedicado e inteligente estudioso, puesto que durante los tres años de guerra la Sociedad de Naciones fue la única tribuna al alcance de la República, no así el Comité de No Intervención, en el que prácticamente era equiparada al bando golpista, y fue objeto de una política exterior particular hasta hoy parcialmente conocida. Esta principal cualidad la reconocen en su prólogo y forros el propio Viñas, Helen Graham y Sebastián Faber, pues durante décadas especialistas y estudiosos 
desecharon por inercia y mal cálculo la posibilidad de que en Ginebra ocurriera algo trascendente para la cuestión española, en el entendido de que Londres colmaba el escenario multilateral de discusión. Este supuesto "no caso" de la Sociedad de Naciones fue motivo de inquietud dentro de esta organización característica del periodo de entreguerras. Si bien algunos historiadores e internacionalistas pudieron entrever la importancia de la extensión ginebrina del drama español, ninguno pudo llevar a cabo un ejercicio de investigación y exposición que incluyera este plano en una necesaria historia internacional. A esta razón se debe que la investigación de David Jorge y su primera gran obra no hayan pasado inadvertidos y hayan merecido otras críticas, coincidentes en que esta edición valenciana habrá de convertirse en una de las más importantes referencias para el conocimiento y estudio de la guerra internacional española en su justa dimensión.

Con un importante soporte en acervos diplomáticos de Europa y América, notoriamente los de la Sociedad de Naciones, de España, Francia, Reino Unido, Irlanda, Portugal, México y Chile, la investigación de Jorge logra una perspectiva que apenas mejoraría con el aprovechamiento de archivos estadounidenses, aunque ésta no representaría una carencia, pues el análisis de Jorge está sustentado en obras de las diplomacias estadounidense, soviética y centroeuropea a propósito del conflicto ibérico. La reconstrucción de la política exterior republicana aprovecha muy bien estas fuentes ante la obvia disgregación de fuentes españolas. Esta política tendrá obvios propósitos de autoconservación y de reconocimiento permanente a una interlocución legítima y exclusiva de la República con el sistema internacional, aunque escasa y tardíamente pasará a la ofensiva frente a la pasividad societaria y las embestidas de la diplomacia oficiosa rebelde y aliada de los rebeldes. Si bien se tenía ya un conocimiento detallado de las afinidades y antipatías que despertaba la causa republicana en el medio exterior, un error grave de interpretación fue trasladarlo tal cual al espacio ginebrino e ingenuamente confiar en el papel neutral de su funcionariado permanente. Lo cierto es, como permite apreciar muy bien David Jorge, que el medio diplomático societario destacó por su antipatía e incriminante equidistancia ante la agresión internacional orquestada en la península por las potencias nazifascistas desde el origen del conflicto, lo cual contribuyó, sin lugar a dudas, a la precipitación del Eje. Muy pocas cosas buenas podían resultar de toda esta concertación ajena y ambigua, no compartida por apenas unos cuantos, anatematizados y con limitado poder de convencimiento como la URSS y México, e inesperados como Nueva Zelanda. Los enemigos de la Sociedad de Naciones y en este caso, de la España republicana siempre fueron más y también fueron decisivos.

No son pocas, pues, las aclaraciones y revelaciones en el libro de David Jorge sobre el curso internacional de la guerra peninsular y de la propia Sociedad de Naciones, con lo cual una cantidad importante de diplomáticos y funcionarios internacionales terminan recolocados, y no en un mejor lugar, en 
esta poco conocida historia; ésta podría ser la más notoria influencia de Viñas, autor demoledor de mitos, en Jorge.

Podría escribir muchas más cosas, pero quizá éstas sólo fueran de mi interés y representen mi interpretación muy personal, a veces atenta y otras descuidada, de la lectura de este imponente volumen, por lo que prefiero dejarlo aquí, confiado en que mi recomendación apenas influirá un poco en la búsqueda y lectura que de manera natural hacen ya los estudiosos e interesados en la guerra española del siglo XX. 